\title{
Poesia e letramento Literário no Ensino Fundamental
}

\author{
Ginete Cavalcante Nunes ${ }^{1}$
}

\begin{abstract}
Resumo: O presente trabalho tem como objetivo apresentar algumas considerações a respeito do trabalho em sala de aula com a poesia e quão significativo pode ser o trabalho com esse gênero, pois, na maioria das vezes o poema acaba sendo trabalhado , como pretexto para análise gramatical ou questionamentos sobre seu aspecto formal .Para discorremos sobre o tema temos como base teórica os trabalhos de Bosi (1977 e 1996), Bakhtin (1997), Barthes(1988), Cosson(2006 e 2014) Cunha (2012), Eagleton (2006), Jouve (2012), Lajolo (1982 e 2000), Pinheiro(2002), Sorrenti (2007), Todorov(2009), Zilberman (1988 e 2003), Zumthor (2007), entre outros,na perspectiva de promover estratégias que aprimorem o ensino da Literatura e de propor livros que despertem o interesse dos alunos pela leitura, este texto justifica-se por tornar possíveis percepções sobre questões do ensino do poema e práticas docentes em literatura mais precisamente com o trabalho com o texto literário, pois este transgride normas, desconstrói a própria linguagem e inaugura mundos possíveis, por meio da transfiguração do real e que desta maneira nos inagamos:Como o uso dos poemas pode influenciar e promover a leitura literária dos alunos do $9^{\circ}$ ano do ensino fundamental? Nosso interesse em investigar o referido assunto também justifica-se pela tentativa de contribuir com os debates a respeito do uso de textos literários e dos livros didáticos de Português no ensino de literatura, promovendo assim o letramento literário, práticas estas norteadas por relações muito complexas, que carecem de estudos, reflexões e discussões.
\end{abstract}

Palavras-chave: Ensino de Literatura; Letramento literário; Poemas.

\section{Poetry and Literary Literacy in Elementary Education}

\begin{abstract}
This paper aims to present some considerations regarding the work in the classroom with poetry and how significant can be working with this genre, because most of the time the poem ends up working as a pretext for parsing or questions about its formal aspect .To carry on about the subject have as theoretical basis the work of Bosi (1977 and 1996), Bakhtin (1997), Barthes (1988), Cosson (2006 and 2014) Cunha (2012), Eagleton (2006 ), Jouve (2012), Lajolo (1982 and 2000), Pine (2002), Sorrenti (2007), Todorov (2009), Zilberman (1988 and 2003), Zumthor (2007), among others, so as to promote strategies that enhance the teaching of literature and to propose books that arouse students' interest in reading, this text is justified for making possible perceptions about the poem educational issues and teaching practices in literature more precisely working with the literary text because this violates standards, deconstructs the language itself and opens possible worlds, through the real transfiguration and thus in inagamos: As the use of poems can influence and promote literary reading of the 9 students year of elementary school? Our interest in investigating the said issue also justified by the attempt to contribute to the discussions about the use of literary texts and the teaching of Portuguese books on literature teaching, thus promoting literary literacy, practice these guided by very complex relationships, that lack of studies, reflections and discussions.
\end{abstract}

Keywords: Literature Teaching; literary literacy; Poems.

${ }^{1}$ Programa de Mestrado Profissional em Letras (PROFLETRAS) da Universidade Federal Rural de Pernambuco - UFRPE. E-mail: ginetecavalcante@bol.com.br 


\section{Introdução}

Sabe-se do imenso valor que a poesia possui, mas são desconhecidas algumas das contribuições que esse gênero reflete na formação dos alunos do ensino fundamental. Atualmente a poesia é tida como uma auxiliadora no processo do letramento literário, sendo que os poemas abordem temas que digam respeito à sociedade e ao nosso tempo, contribuindo para a formação de um leitor crítico e atuante que se identifica como um ser social transformador.

Quanto à literatura que serviu de embasamento teórico, buscou-se pesquisar o que os autores dizem sobre o uso dos poemas na sala de aula e que segundo os autores estes têm uma grande contribuição para o desenvolvimento da leitura e fruição literária, vários pesquisadores tratam deste tema tais como: Bosi (1977 e 1996), Bakhtin (1997), Barthes(1988),Cosson(2006 e 2014) Cunha (2012), Eagleton (2006), Jouve (2012), Lajolo (1982 e 2000), Pinheiro(2002), Sorrenti (2007), Todorov(2009), Zilberman (1988 e 2003), Zumthor (2007), entre outros, na perspectiva de promover estratégias que aprimorem o ensino da Literatura e de propor livros que despertem o interesse dos alunos pela leitura, mas também justifica-se por tornar possíveis percepções sobre questões do ensino do poema e práticas docentes em literatura mais precisamente com o trabalho com o texto literário, pois este transgride normas, desconstrói a própria linguagem e inaugura mundos possíveis, por meio da transfiguração do real e que desta maneira nos indagamos:Como o uso dos poemas pode influenciar e promover a leitura literária dos alunos do $9^{\circ}$ ano do ensino fundamental ?

Percebendo-se a dificuldade que muitos professores enfrentam em sua sala de aula no que concerne ao ato da leitura, principalmente de poemas cabe ressaltar o que diz Léo Cunha (2012):

Infelizmente, poucos são os momentos em que os poemas estão presentes na prática docente. Quando são trazidos pelos educadores para as atividades escolares, muitas vezes são tratados apenas como textos destinados à leitura silenciosa, impressos em papel. (CUNHA, 2012, p. 83)

É de fundamental importância que os educadores selecionem e busquem poemas que possam contribuir para a formação de leitores proficientes e competentes, pois, o trabalho com a poesia realizado em sala de aula pode , sem dúvida alguma fazer o aluno apropriar-se da linguagem literária e também exprimir suas idéias e críticas. Sobre isso é importante notar o que diz Cosson (2014) sobre esse trabalho com a linguagem literária.

A leitura literária conduz a indagações sobre o que somos e o que queremos viver, de tal forma que o diálogo com a literatura traz sempre a possibilidade de avaliação dos valores postos em uma sociedade. Tal fato acontece porque os textos literários guardam palavras e mundos tanto mais verdadeiros quanto mais imaginados, desafiando os discursos prontos da realidade, sobretudo quando se apresentam como verdades únicas e imutáveis. Também porque na literatura encontramos outros caminhos de vida a serem percorridos e possibilidades múltiplas de construir nossas 
identidades. Não bastasse essa ampliação de horizontes , o exercício de imaginação que a leitura de todo o texto literário requer é uma das formas relevantes do leitor assumir a posição de sujeito e só podemos exercer qualquer movimento crítico quando nos reconhecemos como sujeitos . (COSSON, 2014, p. 50)

Cabe ressaltar a relevância que o tema tem para se pensar a construção de uma ação pedagógica mais qualitativa, fazendo da instituição escolar um lugar onde os estudantes passam a vivenciar e apreciar suas diversas formas de criação e expressão, pois educar e aprender não cessam, são momentos fascinantes, infinitos e cheios de magia e prazer.

Sendo assim, para a perspectiva que escolhemos torna-se imprescindível enfatizar a abordagem de Cosson (2006) para nortear o trabalho no que tange à promoção do letramento literário, por entendermos que esta abordagem está totalmente de acordo com o trabalho que se propõe realizar com os poemas em turmas do $9^{\circ}$ ano do Ensino Fundamental e elucidam o ponto de vista, pois, para Cosson (2006) a fruição do texto literário é o trabalho sistemático e contínuo de uso das obras em sala de aula. A ligação com movimento ou dados históricos é secundário.

A poesia é capaz de sensibilizar o ser humano, e nesse sentido evidencia-se a importância de trabalhar o gênero em fase escolar, para tanto deve ser levado em conta tanto a recepção quanto às contribuições da poesia para a promoção da leitura literária.

Como a palavra é objeto de exploração artística na arte literária, sendo-a de uso imensurável no corpo da linguagem, isso permite ao homem a prática de vida, fazendo conhecer-se, com a expectativa de conviver em sociedade,quando interage com esse texto sabendo as diretrizes que o sustenta como ser cultural. Nesse contexto, Tzvetan Todorov (2009) pontua que:

\begin{abstract}
(...) a literatura amplia o nosso universo, incita-nos a imaginar outras maneiras de concebê-lo e organizá-lo. Somos todos feitos do que os outros seres humanos nos dão: primeiro nossos pais, depois aqueles que nos cercam; a literatura abre ao infinito essa possibilidade de interação com os outros e, por isso, nos enriquece infinitamente. Ela nos proporciona sensações insubstituíveis que fazem o mundo real se tornar mais pleno de sentido e mais belo. Longe de ser um simples entretenimento, uma distração reservada às pessoas educadas, ela permite que cada um responda melhor à sua vocação de ser humano (TODOROV, 2009, p. 23-24).
\end{abstract}

Portanto, compete à escola promover e propiciar essa leitura literária, servindo de trampolim para facilitar o gosto pela literatura e leitura de poemas, tornando a leitura poética significativa, estimulando a variedade de experiências, a formação de juízo crítico , a autonomia e responsabilidade leitora dos estudantes do ensino fundamental. 


\section{A Importância da Poesia na Sala de Aula}

Entendemos que o uso de poemas na sala de aula pode se tornar apaixonante tanto à razão quanto à emoção de uma pessoa.

Infelizmente são poucos os professores que trabalham efetivamente com a poesia e poemas em suas salas e quando trabalham dão o tratamento ao poema semelhante ao que se dá a outros gêneros onde infelizmente um poema é tratado da mesma forma que um anúncio, uma bula, um bilhete, uma receita. Isso é a "desmoralização e desqualificação da literatura"

É interessante notar o que diz o escritor mexicano Octavio Paz (1982) sobre a poesia:

A poesia é conhecimento, salvação, poder, abandono. Operação capaz de transformar o mundo, a atividade poética é revolucionária por natureza; exercício espiritual, é um método de libertação interior. A poesia revela este mundo; cria outro.Pão dos eleitos;alimento maldito.Isola;une. (PAZ ,1982, p.15)

O escritor traduz belamente a função e importância da poesia na vida, pois, em verdade, um texto é, ele também, uma dinâmica viva, mesmo que aparentemente congelada numa forma gráfica.

Não nos deixa mentir o poeta:

Penetra surdamente no reino das palavras.

Lá estão os poemas que esperam ser escritos.

Estão paralisados, mas não há desespero,

há calma e frescura na superfície intata.

Ei-los sós e mudos, em estado de dicionário.

Convive com teus poemas, antes de escrevê-los.

Tem paciência se obscuros. Calma, se te provocam.

Espera que cada um se realize e consume

com seu poder de palavra

e seu poder de silêncio.

Não forces o poema a desprender-se do limbo.

Não colhas no chão o poema que se perdeu.

Não adules o poema. Aceita-o

como ele aceitará sua forma definitiva e concentrada

no espaço.

Chega mais perto e contempla as palavras.

Cada uma

tem mil faces secretas sob a face neutra

e te pergunta, sem interesse pela resposta,

pobre ou terrivel, que lhe deres:

Trouxeste a chave?

Repara:

ermas de melodia e conceito

elas se refugiaram na noite, as palavras. 
Ainda úmidas e impregnadas de sono,

rolam num rio dificil e se transformam em desprezo.

(DRUMMOND,1977)

Considera-se então que o texto literário, diante do exposto torna-se um objeto formador e transformador do homem; e que a utilização e interpretação do texto faz-se basilar para que a formação e transformação do indivíduo aconteça.

\title{
Letramento Literário
}

Como sabemos o texto literário tem uma linguagem específica, a conotativa. Em relação à linguagem literária, percebe-se que devido ao pequeno trabalho com ela, os adolescentes e jovens perdem o prazer pela leitura literária, pois já não sabem ler e nem compreender o que leem, já que uma das características do texto literário é a complexidade.

Salientaremos o que dizem os PCNs de Língua Portuguesa sobre o trabalho com o Texto Literário:

\begin{abstract}
A questão do ensino de Literatura ou da leitura literária envolve, portanto, esse exercícios de reconhecimento das singularidades e das propriedades compositivas que matizam um tipo particular de escrita.Com isso , é possível afastar uma série de equívocos que costumam estar presentes na escola em relação aos textos literários , ou seja, tratá-los como expedientes para servir ao ensino das boas maneiras, doa hábitos de higiene, dos deveres do cidadão, dos tópicos gramaticais, das receitas desgastadas do " prazer do texto ",etc. Postos de forma descontextualizada, tais procedimentos pouco ou nada contribuem para a formação de leitores capazes de reconhecer as sutilezas, as particularidades, os sentidos, a extensão e a profundidade das construções literárias . (BRASIL ,1997,p.37,38)
\end{abstract}

O texto literário tem a capacidade de decantar a alma e os sentimentos humanos, sensibilizar os insensíveis e orientar o coração desnorteado.

Faz-se urgente aulas com leituras de qualidade em todos os sentidos da palavra, aulas que priorizem o desenvolvimento do pensamento humano, isso é possível através do texto literário.

Concernente a isso é importante notar o que diz Domício Proença Filho em seu livro $A$ Linguagem Literária, falando sobre o texto literário:

O Texto de literatura pode ainda ser considerado como pretexto para a compreensão da língua, seu ponto de partida, procedimento bastante comum na realidade pedagógica brasileira costuma também ser associado ao estudo de outras manifestações culturais. (PROENÇA FILHO, 2007, p. 17) 
Entendemos que o texto literário não deve ser tratado como um mero texto didático desarraigado de suas especificidades que o tornam literário e trabalhado como mero pano de fundo para se tratar as questões linguísticas, retirando assim o seu contexto e privando os alunos do seu prazer estético de arte, "arte da palavra".

A excelência do texto literário mostra a capacidade humana de usufruir de todos os recursos da linguagem para exteriorizar o que está em oculto, o que é subjetivo e que necessita de reflexão, pois está internalizado no seu ser mais consciente ou inconsciente.

\section{Considerações Finais}

A poesia deve permear a sala de aula e os poemas devem ser trazidos pelos professores e trabalhados de forma significativa na sala de aula e não serem tratados apenas como textos simplesmente destinados à leitura silenciosa. Sendo assim, sem dúvida alguma os alunos se apropriariam de suas características e o letramento literário seria promovido.

As ideias aqui contidas são reflexões, não acabadas, mas com possibilidades, dentre muitas existentes de se pensar com mais carinho no uso da poesia em sala de aula e a contribuição que o uso dos poemas trazem para a promoção da leitura literária no Ensino Fundamental.

Torna-se imprescindível para os professores, portanto, para o profissional da educação, a oportunidade de refletir sobre m o uso dos poemas em suas aulas. Este trabalho de pesquisa, porém não se caracteriza e nem tem a pretensão de ser um ponto final sobre o tema investigado, pois nenhuma pesquisa se esgota em si mesma, mas constitui-se em uma contribuição, abrindo espaço para que novas pesquisas sejam elaboradas tendo como principal função: a transformação social da escola.

A importância da poesia na escola está na sua ação formadora, pois ela representa uma forma que ajudará a ampliar o domínio da linguagem e capacita o leitor na construção do conhecimento.Assim, o texto poético possibilita ao indivíduo conhecer a si mesmo e ao outro e ainda o mundo que está à sua volta .Leva à recriação e à busca de novos sentidos que um texto pode oferecer.

Diante dessas reflexões, é importante reafirmar que a poesia é um dos recursos mais encantadores do processo educacional, visando o crescimento estético, crítico e literário dos estudantes , portanto é imprescindível que se trabalhe de forma eficaz e utilitária esse tão precioso gênero em sala de aula, promovendo assim o Letramento Literário. 
Id on Line Revista Multidisciplinar e de Psicologia

id on Line Multidisciplinary and Psychology Journal

\section{Referências}

BOSI, Alfredo. Leitura de poesia. São Paulo: Editora Ática, 1996.

Paulo,1977.

Alfredo. O ser e o tempo da poesia. São Paulo: Cultrix, Ed.da Universidade de São

BAKHTIN, Mikhail. Estética da criação verbal. São Paulo: Martins Fontes, 1997.

BARTHES, Roland. O prazer do texto. Lisboa: Edições 70, 1988.

Roland. Aula.São Paulo: Cultrix,1978.

BRASIL. Ministério da Educação. Secretaria da Educação Fundamental. Parâmetros Curriculares Nacionais - Língua Portuguesa (1 à $4^{\text {a }}$ séries) - Volume 2 - Brasília: Ministério da Educação, 1997.

CALVINO, Ítalo. "Por que Ler os Clássicos". In: Por que Ler os Clássicos. São Paulo: Cia das Letras, 1993. p. 9-16.

COSSON, Rildo. Letramento literário: teoria e prática - São Paulo: Contexto, 2006. .(2014).Círculos de leitura e letramento literário.São Paulo:Contexto,2014.

COUTINHO, Afrânio. Que é literatura e como ensiná-la. In: Notas de teoria literária. 2. ed. Rio de Janeiro: Civilização Brasileira, 1978. p. 8-15.

CUNHA, Leo (Org.). Poesia para crianças: conceitos, tendências e práticas. Curitiba: Piá, $2012.152 \mathrm{p}$.

DRUMOND DE ANDRADE, Carlos. Procura da Poesia. In Poesia Completa \& Prosa, $4^{\mathrm{a}}$ ed. Rio de Janeiro, Nova Aguillar, 1977.

EAGLETON, Terry. Teoria da Literatura - Uma introdução.São Paulo: Martins Fontes, 2006.

GERALDI,Wanderley João (org.).O texto na sala de aula .São Paulo:Ática,2004.

GIL, A. C. Métodos e técnicas de pesquisa social.4.ed São Paulo: Atlas, 1994.

GIL, A. C. Como elaborar projetos de pesquisa. São Paulo: Atlas, 2010.

JOUVE, Vicente. Por que estudar Literatura?. São Paulo: Parábola, 2012.

LAJOLO, M. Usos e abusos da literatura na escola: Bilac e a literatura escolar na república velha. Rio de Janeiro: Ed. Globo, 1982.

LAJOLO, Marisa. Do mundo da Leitura para a Leitura do Mundo. São Paulo: Ática,2000.

MARCONI, M. A.; LAKATOS, E. M. Metodologia científica. São Paulo: Atlas, 1991. São Paulo: Atlas, 2007.

MARCONI, M. A.; LAKATOS, E. M. Fundamentos de metodologia científica. 
MOREIRA,HERIVELTON.Metodologia da pesquisa para o professor pesquisador LLuiz Gonzaga Caleffe.-2.ed.-Rio de Janeiro:Lamparina,2008.

PAZ, de Octavio. O arco e a lira.Rio de Janeiro: Nova Fronteira,1982.

PINHEIRO, Hélder. Poesia na sala de aula. $2^{a}$ Ed.João Pessoa: Idéia, 2002.

POUND, Ezra. ABC da Literatura. Tradução de: Augusto de Campos e José Paulo Paes. São Paulo: Cultrix, 2006.

PROENÇA FILHO, Domício. A Linguagem Literária. São Paulo: Ática, 2007

SORRENTI, Neusa. A poesia vai à escola: reflexões, comentários e dicas de atividades. Belo Horizonte: Autêntica, 2007.

TAVARES, D.S.S. Da leitura da poesia à poesia da leitura: a contribuição da poesia para o Ensino Médio.300f.Tese (Doutorado em Educação)- Universidade Federal do Rio Grande do Norte,Natal,2007.

TODOROV, Tzvetan. A Literatura em perigo. Trad. Caio Meira. Rio de Janeiro: Difel, 2009.

WAITZ, Inês Regina. "O ensino da literatura e seu espaço de formação" In: Revista de Educação. N. 9, vol. IX, 143 (outubro 2006). Valinhos: AESA, 2006.

ZAPPONE, Mirian H. Y. Modelos de letramento literário e ensino da literatura: problemas e perspectivas. Revista Teoria e Prática da Educação.

v. 11, n. 1, p. 46-60, jan/abr. 2008.

ZILBERMAN, Regina. A leitura e o ensino da literatura. São Paulo: Ed. Contexto,1988.

ZILBERMAN, Regina. A Literatura Infantil na Escola. São Paulo: Gobal,2003.

ZILBERMAN, R.; SILVA, Ezequiel T. (Org.). Leitura: perspectivas interdisciplinares. São Paulo: Ática, 1988.

ZUMTHOR, Paul. Performance, Recepção, Leitura.Tradução de Jeruza Pires e Suely Fenerich.2.ed. São Paulo: Cosac Naify, 2007.

\section{Como citar este artigo (Formato ABNT):}

NUNES, Ginete C. Poesia e letramento no Ensino Fundamental. Id on Line Revista de Psicologia, Fevereiro de 2016, vol.10, n.29. p. 152-159. ISSN 1981-1179. 